Original Research Paper

\title{
Estimation of Natural and Artificial Recharge of Shahreza Plain Groundwater in Isfahan Using CRD and Hantush Models
}

\author{
${ }^{1}$ Mohsen Nekooei, ${ }^{1}$ Jahangir Abedi Koupai, ${ }^{1}$ Saeid Eslamian, \\ ${ }^{2}$ Vijay P. Singh and ${ }^{3}$ Kaveh Ostad-Ali-Askari \\ ${ }^{I}$ Department of Water Engineering, College of Agriculture, Isfahan University of Technology, Isfahan, Iran \\ ${ }^{2}$ Department of Biological and Agricultural Engineering and Zachry, \\ Department of Civil Engineering, Texas A and M University, \\ 321 Scoates Hall, 2117 TAMU, College Station, Texas, USA \\ ${ }^{3}$ Department of Civil Engineering, Najafabad Branch, Islamic Azad University, Najafabad, Iran
}

\section{Article history}

Received: 13-11-2018

Revised: $13-01-2020$

Accepted: 08-06-2020

Corresponding Author: Mohsen Nekooei

Department of Water

Engineering, College of Agriculture, Isfahan University of Technology, Isfahan, Iran Email: Mohsen.nekoei@gmail.com

\begin{abstract}
Cumulative Rainfall Departure model (CRD) is widely used for estimation of ground natural recharge. This model is based on the groundwater balance and it requires random parameters. Moreover, an increase in the static level under artificial recharge facility is simulated using diffusion equations. Since Shahreza Plain is located in an arid and semi-arid area and given that rainfall is the major recharge source in such regions, in this study CRD model is applied in order to estimate natural recharge of Shahreza Plain groundwater. The amount of groundwater basin fed by rainfall was estimated about 177.2 million cubic meters using the CRD model. Also, by investigating and comparing available artificial recharge plans in Shahreza Plain it was known that in Kohrouyeh Project due to high soil permeability the increase in water table depth was higher than other projects and it achieves the maximum level of the water table within less time. By investigating the course of groundwater quality change in upstream and downstream boreholes of artificial recharge plans and given dewatering periods, we found that artificial recharge plans are generally effective in improving groundwater quality in the direction of groundwater movement but these changes are not significant. Hence, it is demonstrated that groundwater change mostly depends on the groundwater drop.
\end{abstract}

Keywords: Artificial Recharge, Shahreza Plain, Groundwater Quality, Cumulative Rainfall Departure Model, Hantush Model

\section{Introduction}

One of the effective ways to supply the water required by different sectors, particularly in arid and semi-arid regions and also overcoming the crisis of drought is to assist in increasing groundwater reservoirs and preventing Qanat dry out, control of floods and basins artificial recharge (Behnia, 1988). In the last few decades, artificial recharge methods for restoring groundwater resources dried out due to excessive exploitation in arid regions has been applied in regions where there are coarse grains and moderate slope alluvial fans (Minnig et al., 2018).

Rainfall is the main source of groundwater resources. Every year, a certain amount of rainfall or surface currents join groundwater resources known as an effective recharge and it is defined as the amount of water penetrated into lower layers of the unsaturated area and heightens water table (Barry et al., 1999).

In South Africa, simulation of water fluctuation in water table against rainfall time was conducted in order to determine recharge value. The result of this method is the same as that in CRD. This model is applicable to those regions where the only recharge source is rainfall. Therefore, concerning the regions where there is water flow between basins, it may not be applicable (Gerdefaramarzi and Koupaei, 2011).

Khazaei et al. (2003) studied groundwater recharge in arid and semi-arid regions of the south of Iran and they proposed a model in which estimated water table 
is consistent to the water table measured from observed boreholes. Sensitivity analysis indicated that when rainfall in these regions is replaced by the rainfall in moderate and highlands, recharge value is reduced by $42-87 \%$. The results indicated that in order to achieve an exact estimation of recharge it is necessary to divide the region into similar hydrologic areas (Rebhun and Schwarz, 1968).

Artificial recharge includes water into a permeable formation; this method is widely used for protecting aquifers and utilization of stored water under the ground (Bouwer, 2002).

Matson 1961 believes that high permeability and soil depth are two factors that make the soil suitable for artificial recharge. He believes that light soil lands are the best-qualified ones for artificial recharge.

So many studies have been done about artificial recharge principles, water penetration into soil and formation of hydraulic mound under recharge facilities that have led to the proposition of theoretical equations for expressing hydraulic mound behavior (Cook et al., 1989). By reaching wetting front to the water table, the hydraulic mound develops, development of hydraulic mound under the modified bed of rivers may be considered as 2D (Khazaei et al., 2003).

In order to evaluate the impacts of artificial recharge on the water table, many computer programs have been developed. One of them is Glover and Hantush's analytical solution for rectangular and circular ponds that predicts the value of the mound growth and shape (Behnke, 1969).

Groundwater recharge via rainfall is the most important recharge source in Southern Shahreza Area. The average annual rainfall in this region is $204 \mathrm{~mm}$ of which a small part is stored and much of it's evaporates. The aim of the present study is the estimation of natural recharge value in Southern Shahreza Plain using CRD model and investigating the impact of artificial recharge plans on the quantity and quality of groundwater of this region (WMSD, 2007).

\section{Materials and Methods}

\section{Cumulative Rainfall Departure Model}

CRD model was initially proposed by Bredenkamp et al., 1995. The theory of this method is based on groundwater balance in an aquifer (Raeisi and Afzal, 1997). This balance may be expressed as follows:

$$
R=Q_{p}+Q_{\text {out }}-Q_{\text {in }}+\Delta h_{i} \times A \times S
$$

Where:

$R=$ Total Aquifer Recharge $\left\lfloor L^{3} / T\right\rfloor$

$$
\begin{aligned}
Q_{p}= & \text { Pumping Outflow }\left\lfloor L^{3} / T\right\rfloor \\
Q_{\text {out }}= & \text { Aquifer Outflow }\left\lfloor L^{3} / T\right\rfloor \\
Q_{\text {in }}= & \text { Aquifer Inflow }\left\lfloor L^{3} / T\right\rfloor \\
\Delta h_{i}= & \text { Water level change within certain time } \\
& \text { interval }[L] \\
A= & \text { Aquifer area }\left[L^{2}\right] \\
S= & \text { aquifer storability coefficient }
\end{aligned}
$$

Bredenkamp assumed a linear relationship between monthly changes of water level and cumulative rainfall departure. This relationship may be expressed as follows:

$$
C R D_{i}=C R D_{i-1}+\left(p_{i}-C\right)
$$

Where:

$$
\begin{aligned}
C R D_{i}= & \text { Cumulative Rainfall Departure for } i^{\text {th }} \text { month } \\
& (\text { mm. }) ;[\mathrm{L}] \\
C R D_{i-1}= & \text { Cumulative Rainfall Departure for }-i 1^{\text {th }} \\
& (\text { mm. }) ;[\mathrm{L}] \\
= & \text { Rainfall }\left(\mathrm{mm} . / \text { month) }\left\lfloor L^{3} / T\right\rfloor\right. \\
P_{i} \quad & \text { A threshold value where recharge does } \\
& \text { notoccur anymore }
\end{aligned}
$$

This equation indicates the relationship between the two values of CRD in two consecutive periods. The general equation used for converting pure recharge from the CRD model is as follows:

$h_{i}=h_{i-1}+\frac{R}{S}+\frac{Q_{i n}-Q_{o u t}}{S \times A}-\frac{Q_{p}}{S \times A}$

where, represents pure recharge expressed as a coefficient of rainfall. $h_{i}$ is the frequency in ith month and $h_{i}-1$ is the frequency in $i-1$ th month calculated on the meter. The values of pumping outflow and rainfall statistics are usually measured accurately. Therefore, if the inflow and storability coefficient is known, the only unknown parameter in above equation will be $R$. Using CRD model water table fluctuations obtained from Equation (3) is portrayed against measured water table measured from observed boreholes. The best recharge estimation is achieved when the difference between measured and estimated water table values are minimized that will be possible through shrinking the amount of root mean square error between measured and calculated water table values.

\section{Hantush's Model}

The equation that predicts the value of groundwater level rise or drops in artificial recharging ponds proposed by (Hantush, 1967). This model could yield a good 
estimation of groundwater bed recharge value and it is applied for rectangular recharge level (Fig. 1).

Prediction of hydraulic mound development of an open aquifer under rectangular recharge ponds is performed via the following equation:

$h_{x, y, t}-H=\frac{V_{a} t}{4 f}\left\{F\left[\left(\frac{W}{2}+x\right) n,\left(\frac{L}{2}+y\right) n\right]\right.$

$+F\left[\left(\frac{W}{2}+x\right) n,\left(\frac{L}{2}-y\right) n\right]$

$\left.+F\left[\left(\frac{W}{2}-x\right) n,\left(\frac{L}{2}+y\right) n\right]+F\left[\left(\frac{W}{2}-x\right) n,\left(\frac{L}{2}-y\right) n\right]\right\}$

$F(\alpha, \beta)=$ error function $=\int_{0}^{1}\left[\operatorname{erf}\left(\alpha t^{-0.5}\right) \times \operatorname{erf}\left(\beta t^{-0.5}\right)\right]$

$n=\left(\frac{4 t T}{f}\right) \wedge(-0.5)$

$\alpha=\left(\frac{W}{2} \pm x\right) n$

$\beta=\left(\frac{L}{2} \pm y\right) n$

If $h_{x, y, t}$ is more than $0.5 \mathrm{H}$, the results of Equation (4) would not be accurate. $T$ parameter must be calculated from the time when wetting front gains, a level same as groundwater level that usually occurs a few days after the beginning of infiltration (MorelSeytoux et al., 1990).

Equation (4) may be applied for estimation of groundwater level decline that is calculated from the time of infiltration stop time (Dettinger, 1989):

$h_{x, y, t}-H=Z(x, y, t)-Z(x, y, t)$ where, $t s$ represents the time of water infiltration stoppage.

Since at the time of groundwater level decline, the area of water saturation is drained, $f$ value must be considered for drainage conditions that are usually less than real $f$ value (Xu and van Tonder, 2001).

\section{Shahreza Plain Study}

Shahreza County is located at 85 th $\mathrm{Km}$ of the south of Isfahan. Shahreza's $2500 \mathrm{~km}^{2}$ basin originates from Gavkhouni basin chief branches and Shahreza County is located in its outlet.

Climatic conditions of this region according to De Martonne and Coupon's method is arid and it is aridcold based on Emberger's method. The average annual rainfall of this region is $204 \mathrm{~mm}$ and its annual evaporation rate is $2650 \mathrm{~mm}$. Where the maximum value of rainfall in July equals $410 \mathrm{~mm}$ and the minimum value of rainfall in January equals $65 \mathrm{~mm}$. The maximum absolute temperature of this region is $42^{\circ} \mathrm{C}$ and minimum temperature is $-27^{\circ} \mathrm{C}$.

The formations of the second geologic period have produced one of the most important water reservoirs of this basin.

Groundwater flows from the southwest and west highlands toward Aminabad, Esfarjan, Kohrouyeh and Sourmandeh valleys and also Dehaghan mouth in west Shahreza toward the centre of the plain and finally toward the northeast, namely an aperture opened to South Mahyar.

The Groundwater level in south Shahreza is 20-60 $\mathrm{m}$. The water discharged from groundwater reservoirs within the studied area based on an annual table of Zayandeh-rud basin resources status from 350 deep and semi-deep boreholes is 1.52 million cubic meters during 2007-2008 (Fig. 2).

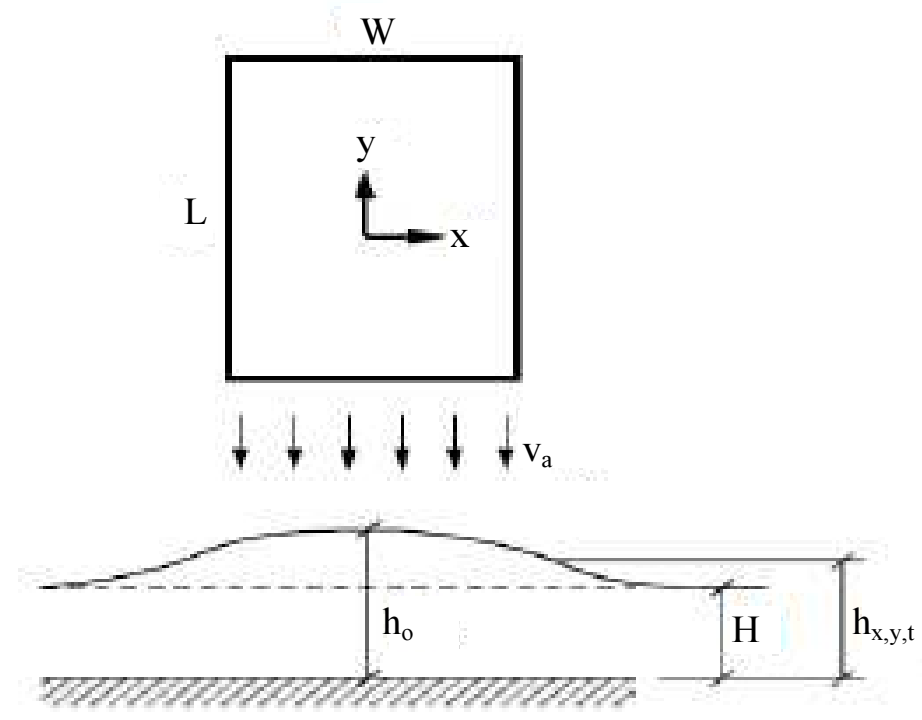

Fig. 1: Estimation of discharge value under rectangular ponds using Hantush model 


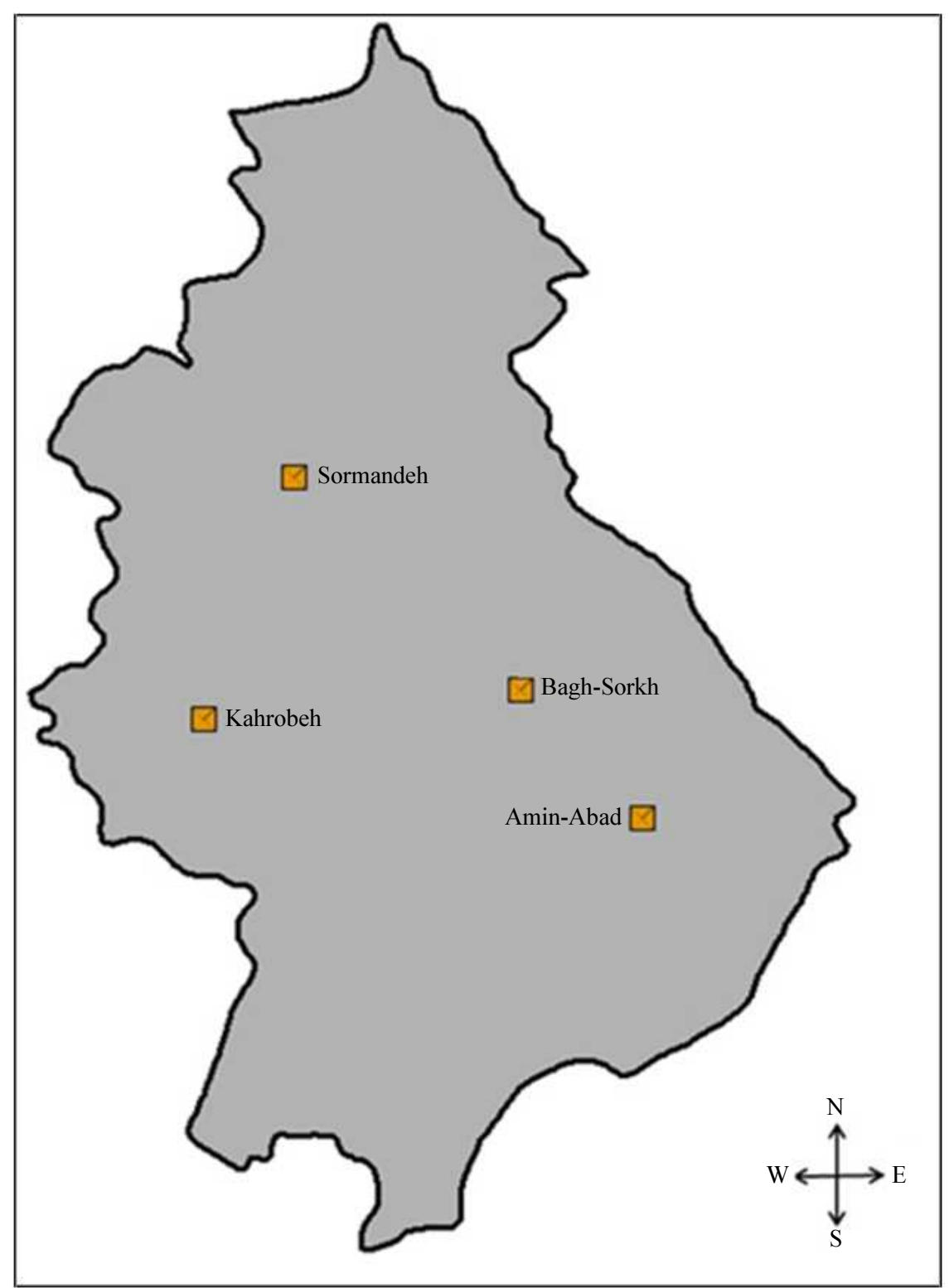

Fig. 2: Position of meteorological stations of the studied area

The average hydraulic gradient of the bed along the direction of flow calculated from Mahyar-Shahreza Plain groundwater balance map equals $0.7 \%$, but this figure is certainly higher under current conditions of the aquifer; so that $2 \%$ value could be applied as a suitable approximation of current conditions of the hydrologic gradient of this aquifer.

The total porosity values measured on surface samples were taken from $0-0.6 \mathrm{~m}$ of depth equals $14.4 \%$ and this figure is $27.7 \%$ in $2.6 \mathrm{~m}$ of depth; but considering the degree of aquifer subsidence and gradual reduction of porosity with depth increase that corresponds the thickness and weight of aquifer and given the results obtained from tests of pumping, effective porosity of aquifer equals aquifer storability coefficient that is equal to $0.558 \%$. Based on field studies, we could consider the mean thickness of aquifer equal to $b=70 \mathrm{~m}$. The value of a specific retention coefficient of surface soil in this region is calculated as $11 \%$.

In order to evaluate artificial recharge plans, four plans were selected, namely Kohrouyeh, Sourmandeh, Bagh Sorkh and Aminabad; specifications of Kohrouyeh project are presented in Table 1 (WMSD, 2007).

In the next stage, for the purpose of estimating natural recharge value of south Shahreza Plain using CRD model and given the position of 8 pluviometer stations on the map, the under-study area was divided into 8 areas and piezometric boreholes of each area were determined. The area of the station located in the studied area is $1000 \mathrm{~km}^{2}$. This area indeed covers 27 observational 
boreholes on which Isfahan Regional water Organization has measured water height. The monthly statistics related to water level absolute height (absolute difference of the borehole target point with water surface depth from target point) were obtained during October 1999 to October 2008 using Isfahan Water Organization and Thiessen network related to these boreholes were portrayed using Arc GIS software (Fig. 3).

In order to statistically investigate the qualitative factors of the south Shahreza groundwater resources, we used Excel and SPSS software. In addition, correlation coefficients between the qualitative parameters of these groundwater resources were calculated and then its quality was studied using Shuler and Wilcox graphs. Using Arc GIS software, the zoning maps of qualitative parameters of the plain were portrayed for 2 periods, namely 1995-2000 and 2001-2007 (Gerdefaramarzi and Koupaei, 2011).

We then drew the diagram of groundwater quality changes against water table decline diagram and studied their relationships.

Table 1: Specifications of artificial recharge projects

\begin{tabular}{lrlr}
\hline Layer thickness $(\mathrm{mm})$ & \multicolumn{1}{c}{ 이 } & $\mathrm{Kz}(\mathrm{m} /$ day $)$ & 1.5 \\
\hline Permeability $\left(\mathrm{m}^{2}\right)$ & 1.00 & $\mathrm{Kx}(\mathrm{m} /$ day $)$ & 15.00 \\
Water period $(\mathrm{t})$ & 30.00 & $\mathrm{~T}\left(\mathrm{~m}^{2} /\right.$ day $)$ & 300.00 \\
Effective porosity (No dimension) & 0.25 & Water height $(\mathrm{m})$ & 2.00 \\
Pond length $(\mathrm{m})$ & 800.00 & Soil suction $(\mathrm{m})$ & -0.05 \\
Pond width $(\mathrm{m})$ & 70.00 & Surface depth $(\mathrm{m})$ & 30.00 \\
\hline
\end{tabular}

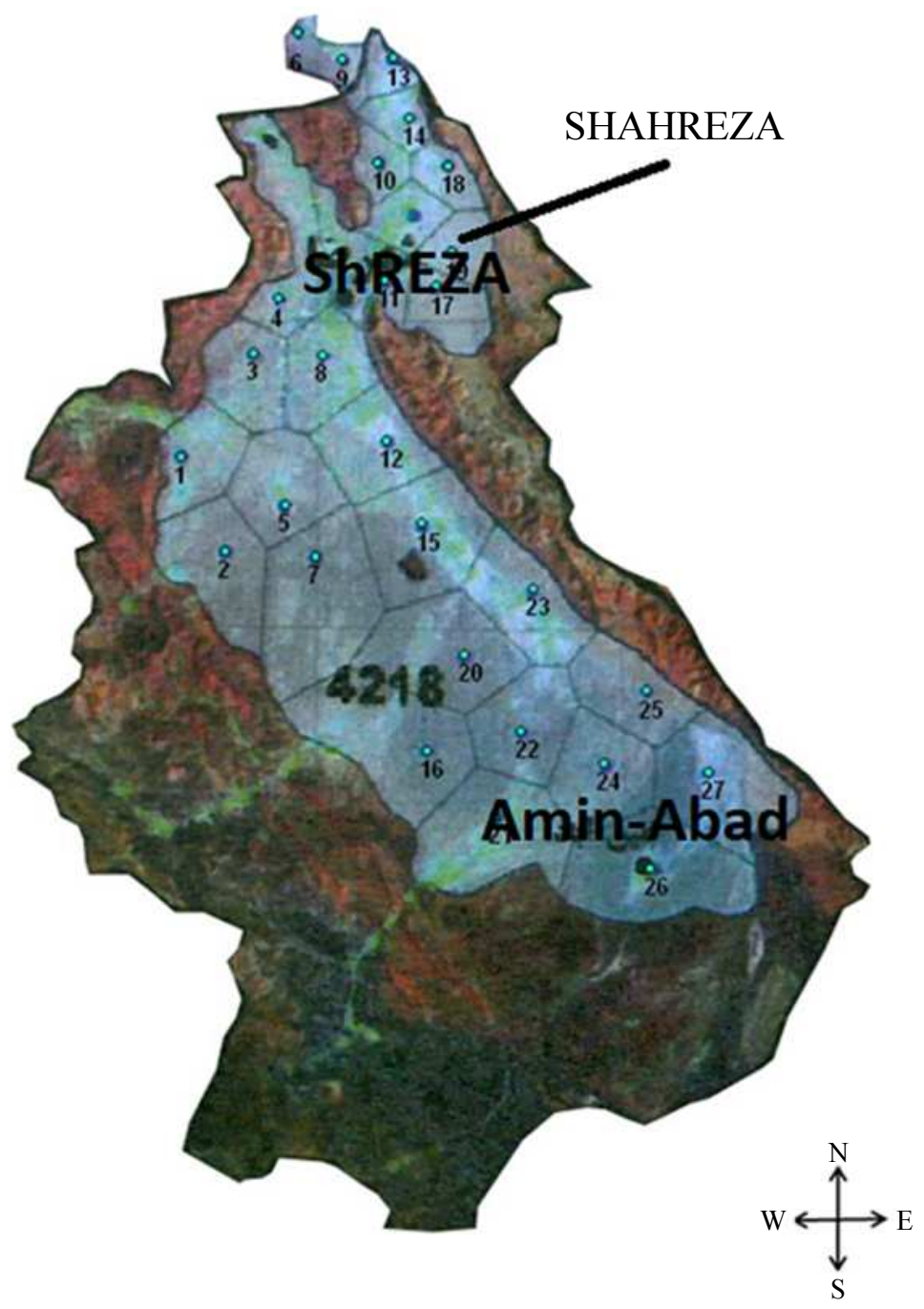

Fig. 3: Position and Thiessen network of piezometric boreholes 
After investigating the course of changes of groundwater quality, the effects of artificial recharge plans on the quality of studied groundwater given the water absorption periods were determined. For this purpose, the quality of water in two boreholes (one located in upstream and the other in downstream) within the area of artificial recharge projects in Aminabad and Kohrouyeh was studied. Given water absorption periods of these projects and the course of groundwater quality change course in abovementioned boreholes, the effect of artificial recharge projects on the quality of groundwater was studied (Mousavi and Kirkham, 1978). Table 2 displays variant areas (9 zones) which shows the result of the CRD model. The most cumulative rainfall departure is $67 \%$ which name is Laricheh with 0/123 RMSE and the least cumulative rainfall departure is $22.18 \%$ with $0 / 206$ RMSE. The range of RMSE is between $0 / 123$ and $0 / 261$ but the range of CRD is between 22.18 and $67 \%$. The second cumulative is $48.14 \%$ (Houk).

\section{Results and Discussion}

After predicting the level of groundwater using CRD model, its related diagram was superimposed on the groundwater level diagram measured from piezometric boreholes and also monthly rainfall diagram in order to investigate their results. Therefore, given water balance equation and model results, the value of recharge for each eight zones was calculated.

The last step is the optimization of this method using minimization of root mean square error between measured data and the calculated water table. The best-

optimized value in the least root means a square error was obtained. The value of Root Means Square Error (RMSE) was calculated using the following equation in which $F$ represents measured values and $f$ represents calculated values and $\mathrm{n}$ is the number of observations:

$$
R M S E=\sqrt{\frac{\sum\left(F\left(x_{1}, x_{2}, \ldots, x_{n}\right)-f\left(x_{1}, x_{2}, \ldots, x_{n}\right)\right)^{2}}{n}}
$$

Using formulas (6) to (8), the water table in each zone was simulated an instance of which is presented in the (Fig. 4).

As is observed in the simulated diagram related to aminabad area, the changing course of the CRD diagram follows the changing course of groundwater level changes (Fig. 4). According to this figure, when cumulative rainfall departure is negative (rainfall quantity is less than mean value), the changing course of the simulated diagram is in descending order. This descending movement is due to the effect of insufficient rainfall in the past months.

Table 2: The results of CRD model

\begin{tabular}{lll}
\hline Area & CRD & RMSE \\
\hline Maghsoudbeig & $22.25 \%$ & $0 / 222$ \\
Laricheh & $67 \%$ & $0 / 123$ \\
Aminabad & $26.22 \%$ & $0 / 251$ \\
Houk & $48.14 \%$ & $0 / 251$ \\
Esfarjan & $29.7 \%$ & $0 / 254$ \\
Aliakbar & $22.18 \%$ & $0 / 206$ \\
Shahreza & $27.14 \%$ & $0 / 223$ \\
Kohrouyeh & $36.19 \%$ & $0 / 261$ \\
Mean & $34.61 \%$ & $0 / 223$ \\
\hline
\end{tabular}

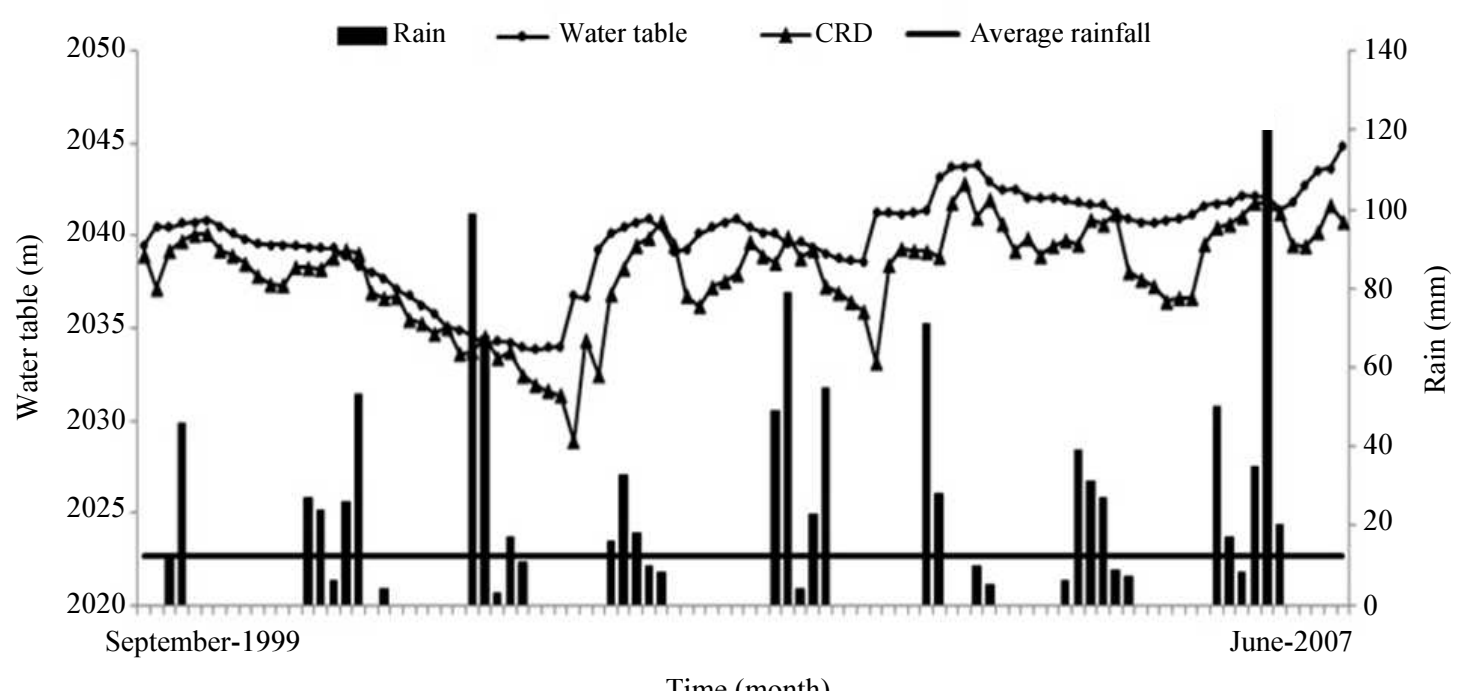

Time (month)

Fig. 4: The results of CRD- based simulation concerning Aminabad area 
As is observed, in general, the simulated diagram follows the real water table diagram; but in some months, this difference becomes significant. This may be attributed to the different pumping amounts during different months of the year.

On the other hand, inconsistency in the general course of two diagrams may be attributed to the measurement error concerning some parameters. Sensitivity analysis indicated that estimation of recharge quantity's sensitivity to recharge coefficient parameter is more than other parameters and the minor difference in "S" value may yield different results concerning simulated recharge value and water level value; also, the least sensitivity relates to the outflow of the aquifer. Hence, the storability coefficient must be measured with high accuracy which is presented in the results related to the calculated recharge value using the CRD model and also RMSE of each zone as indicated in Table 2.

Based on the results indicated in Table 2 and using the CRD model, groundwater recharge in the south Shahreza
Plain as a percentage of rainfall was calculated about $34.61 \%$. Given the average rainfall in this area that is 204 $\mathrm{mm}$ annual 1 and the area of this region that is $2510 \mathrm{~km}_{2}$, the annual groundwater recharge amount of this basin from rainfall is estimated about 177.2 million cubic meters. It is observed that because " $\mathrm{S}$ " parameter is not measured accurately, RMSE values are relatively big. For better understanding the conditions of groundwater under artificial recharge facilities using Equation (4) and (Table 1), the diagrams related to infiltration speed, water table, wetting front movement changes over time and also impact range of water table increase at recharge time were portrayed as an instance of which is presented in (Fig. 5).

The results demonstrated that concerning Kohrouyeh artificial recharge plan, due to high infiltration the degree of water table increase under the system boreholes, the positive effect of impoundment in these facilities on the water table increase is evident. This effect was not similar in all boreholes. In some boreholes such as Soular and is higher compared to other projects.
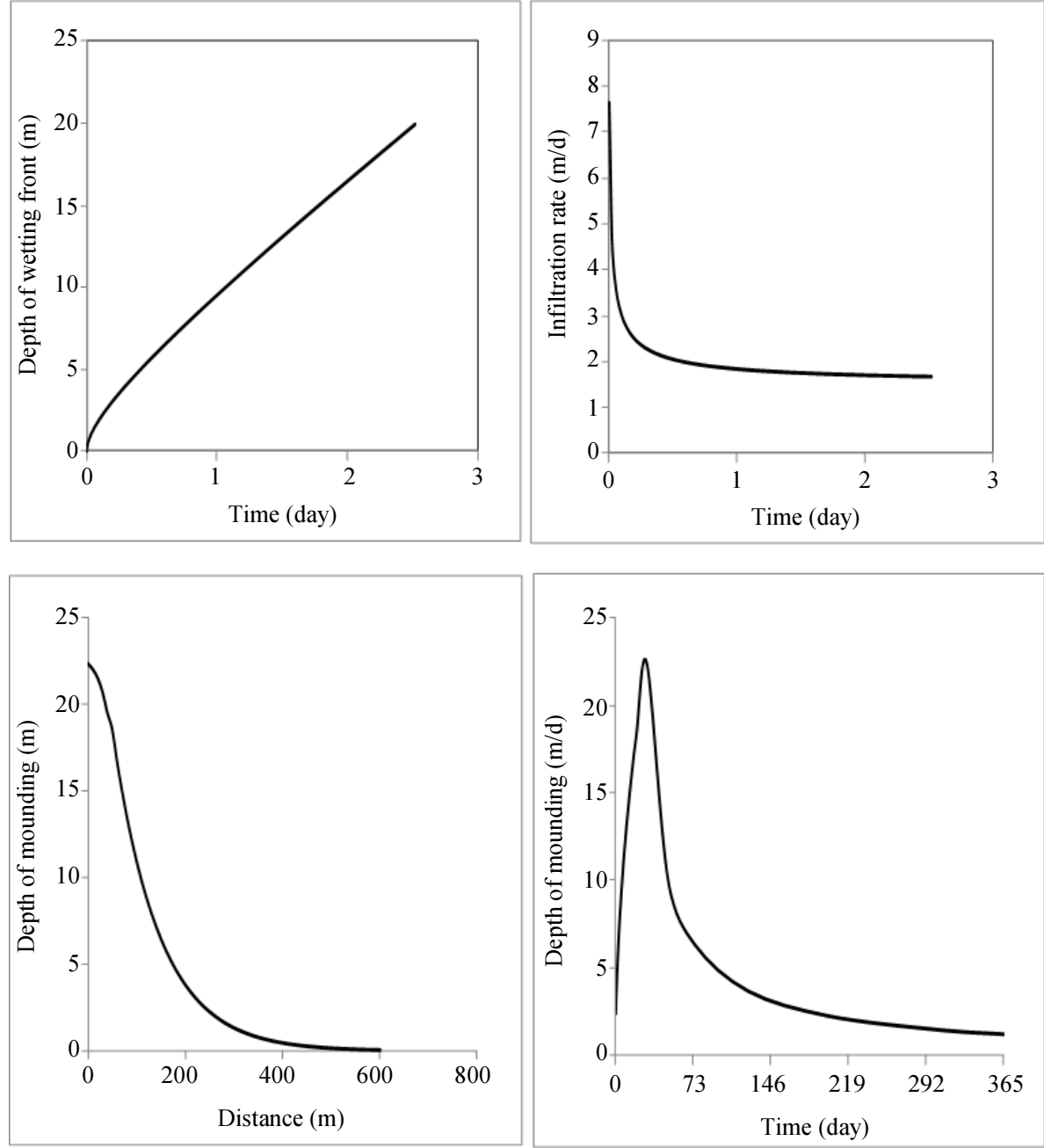

Fig. 5: The results of the simulations concerning Kohrouye artificial recharge plan 

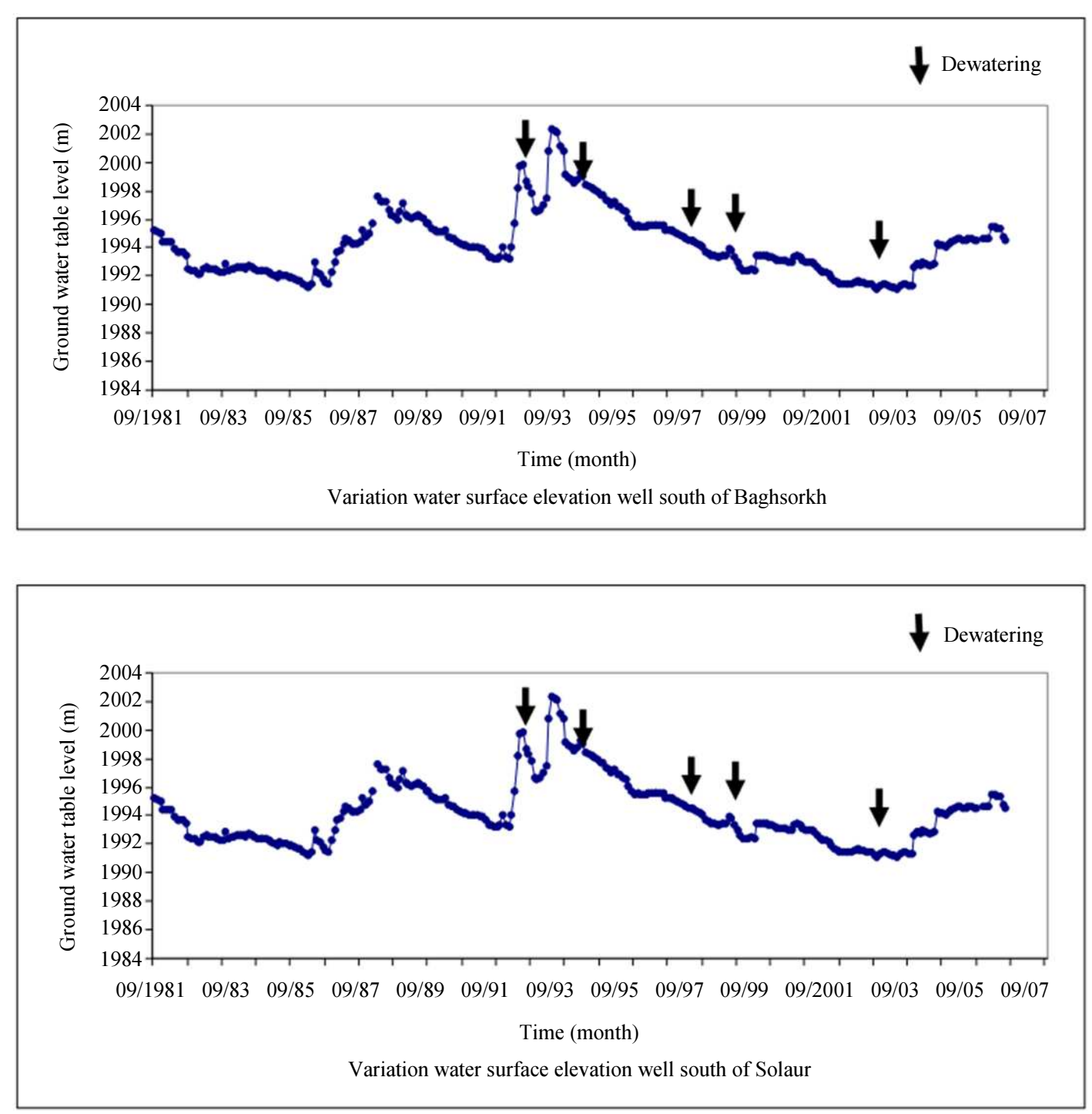

Fig. 6: Positive effect of impoundment in studied facilities on the increased water table

By investigating the hydrograph of observed south Bagh Sorkh boreholes, water table increase one month after impoundment particularly during periods 1991-1992 and 1997-1998 was highly significant and up to the 5meter increase in water table was observed (Fig. 6) (Attarzadeh, 1996).

In order to investigate the effect of artificial recharge systems on the quality of groundwater quality in the studied area, we firstly investigated the results of the chemical analysis conducted on the groundwater of 29 boreholes existing in the area.

Moreover, for studying the quality of groundwater in the studied area in terms of drinkability and agriculture, we portrayed Shuler and Wilcox diagrams respectively. The results indicated that as we move to the northern areas of the plain the quality of water intends to deteriorate and become undrinkable.
Moreover, in southern areas and near southern highlands of south Shahreza Plain, the quality of water could be placed in $\mathrm{C} 2-\mathrm{S} 1$ to $\mathrm{C} 3-\mathrm{S} 1$ categories that seem suitable for agricultural applications.

At the final stage, using Arc GIS, we studied the zoning map of qualitative parameters in two periods, namely 1995-2000 and 2001-2007 an instance of which is indicated in (Fig. 7 and 8). Based on these maps, the concentration of qualitative parameters in groundwater gradually increases in the direction of groundwater, namely from the south, southwest and west of the plain toward the north and northeast. Since the artificial recharge facilities of this plain are mostly located in the south and west of this area, the effect of these facilities on the quality of groundwater could be considered as one reason why such results have been gained from zoning maps of qualitative parameters. 


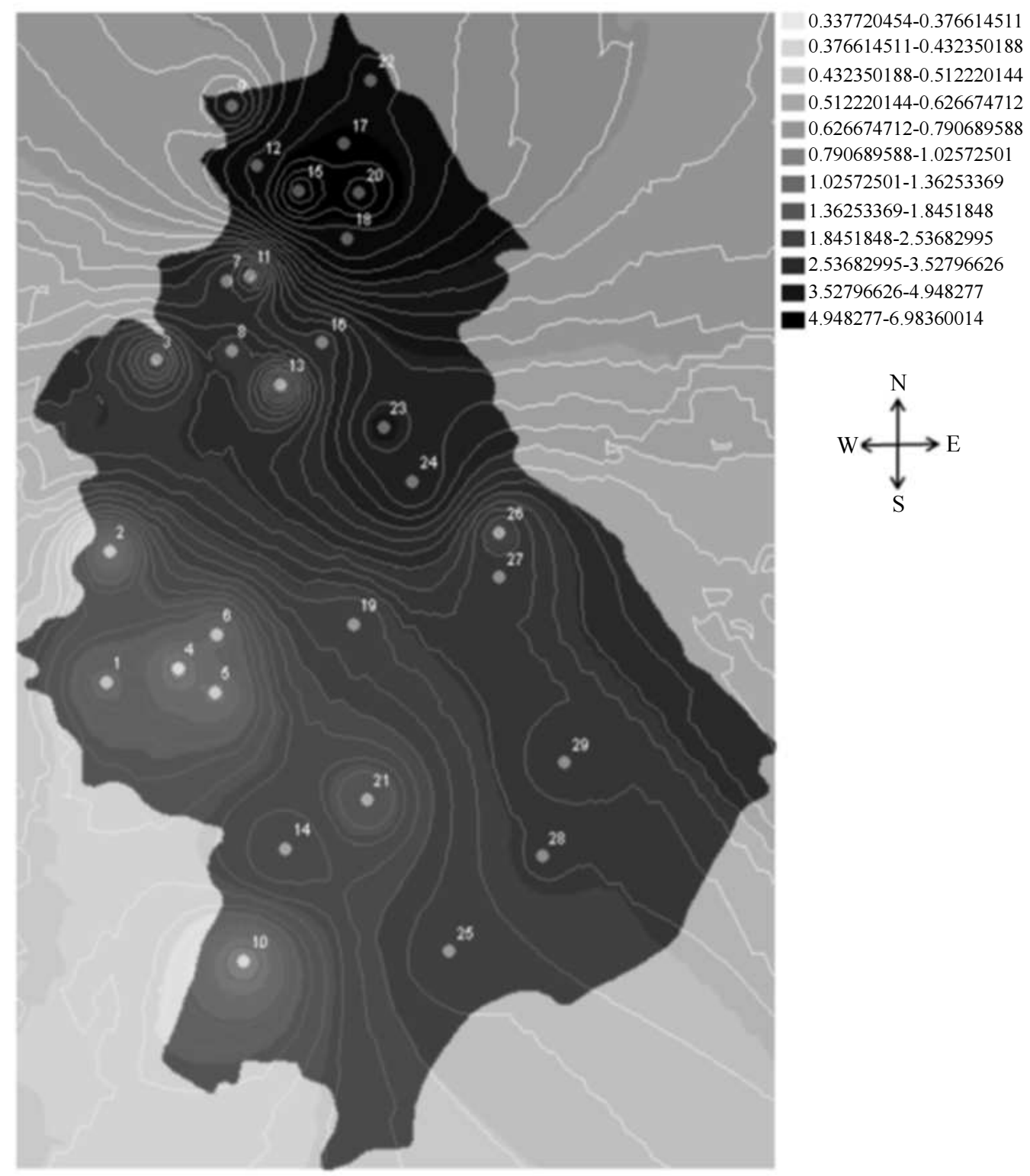

Fig. 7: EC parameter zoning related to the studied area during 1995-2000

By drawing the groundwater quality change diagram based on the water table change trend, it was demonstrated that by groundwater level reduction in the region, the concentration of qualitative parameters increases. It was also observed that the concentration of qualitative parameters has increased during the considered period. (Fig. 9) shows the results related to EC parameter.

The above figure shows the same EC concentration during the period of time is between 203 and 2.7. and the static level is almost equal the concentration from 1995 to 2000 is between 1995 to 2000 but Suddenly it decreases
Static level until 2003 then it increases until 2006.

In order to evaluate the effect of artificial recharge projects on the quality of groundwater, we compared the groundwater quality change course related to Panjegan and Bagh Choghadek boreholes located in upstream and downstream of Kohrouyeh facilities respectively and it was demonstrated that in Bagh Choghadek borehole (downstream), groundwater quality after artificial recharge via facilities experienced more improvement than Panjegan borehole. It must be noted that in some cases, despite impoundment, groundwater quality did not change (Fig. 10). 

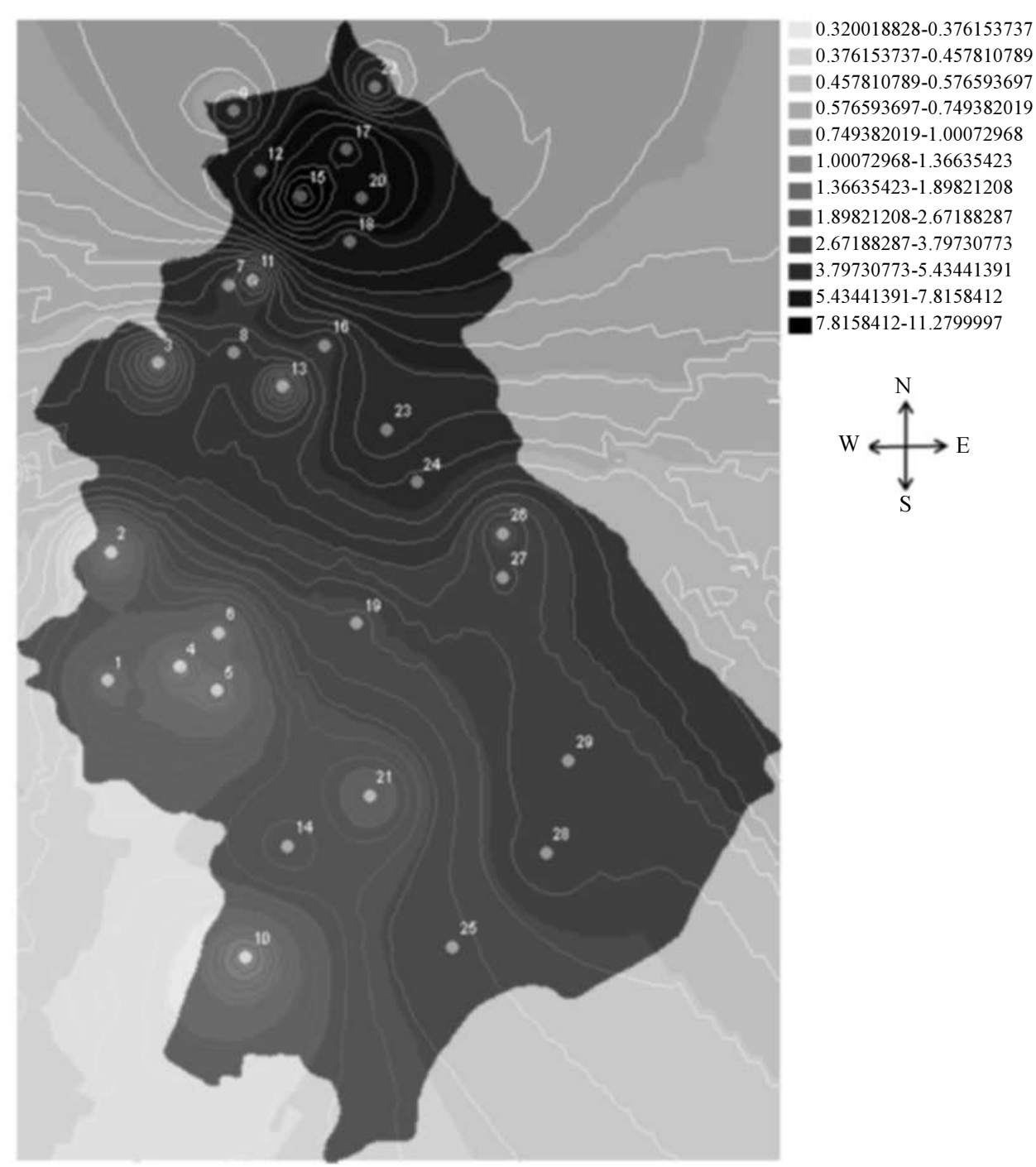

Fig. 8: EC parameter zoning related to the studied area during 2001- 2007

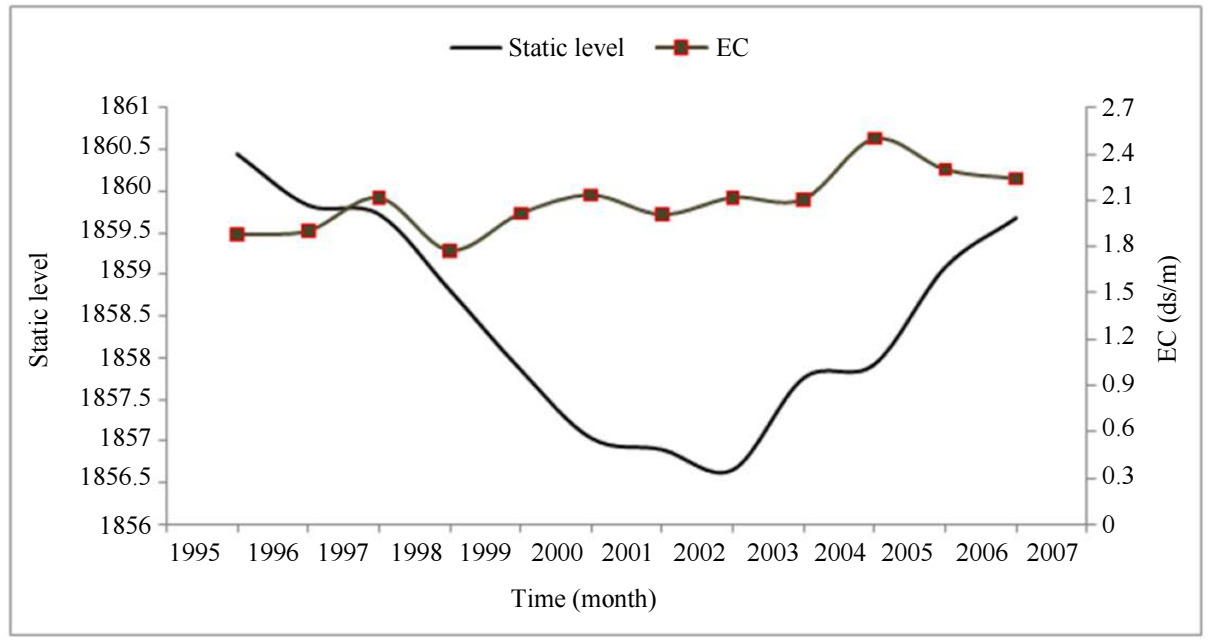

Fig. 9: The mean of EC changes throughout the region 


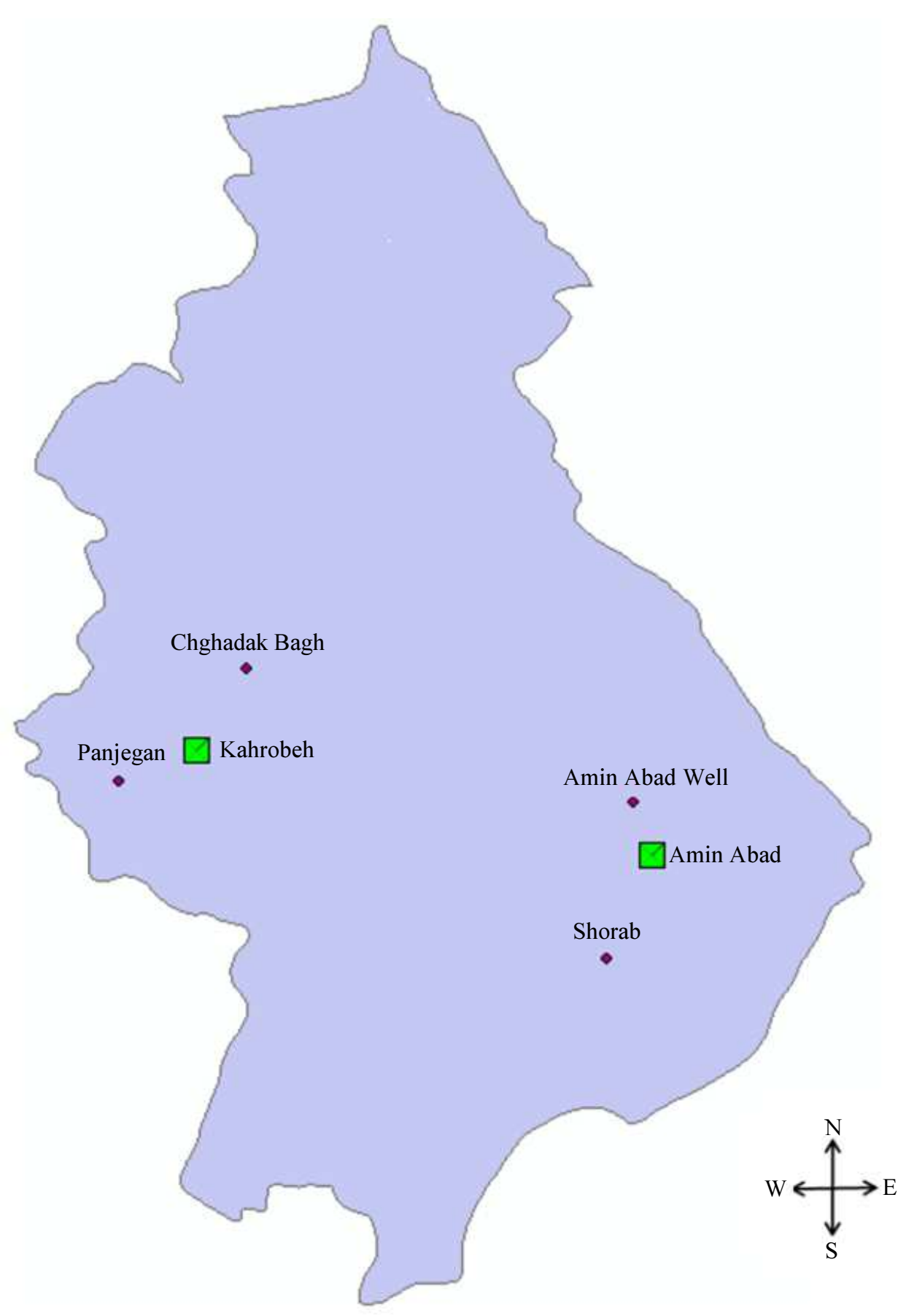

Fig. 10: The position of studied boreholes related to artificial recharge facilities

By comparing the results obtained through investigating the effect of artificial recharge projects on the quality of groundwater quality and also the effect of waterbed decline on the groundwater quality change it was observed that groundwater quality change is mostly dependent on the groundwater level decline; hence, despite the positive effect of artificial recharge facilities on the quality of groundwater, these projects are most effective on the increase of groundwater level (Fig. 11).

The EC concentration is between 0.3 to 0.6 but the Static level fluctuates from 2001 to 2004 (Chaghad Well) but the EC concentration is about 6.4 to 6.6 during the time although the Static level fluctuates all the time. (Panjegan well). 


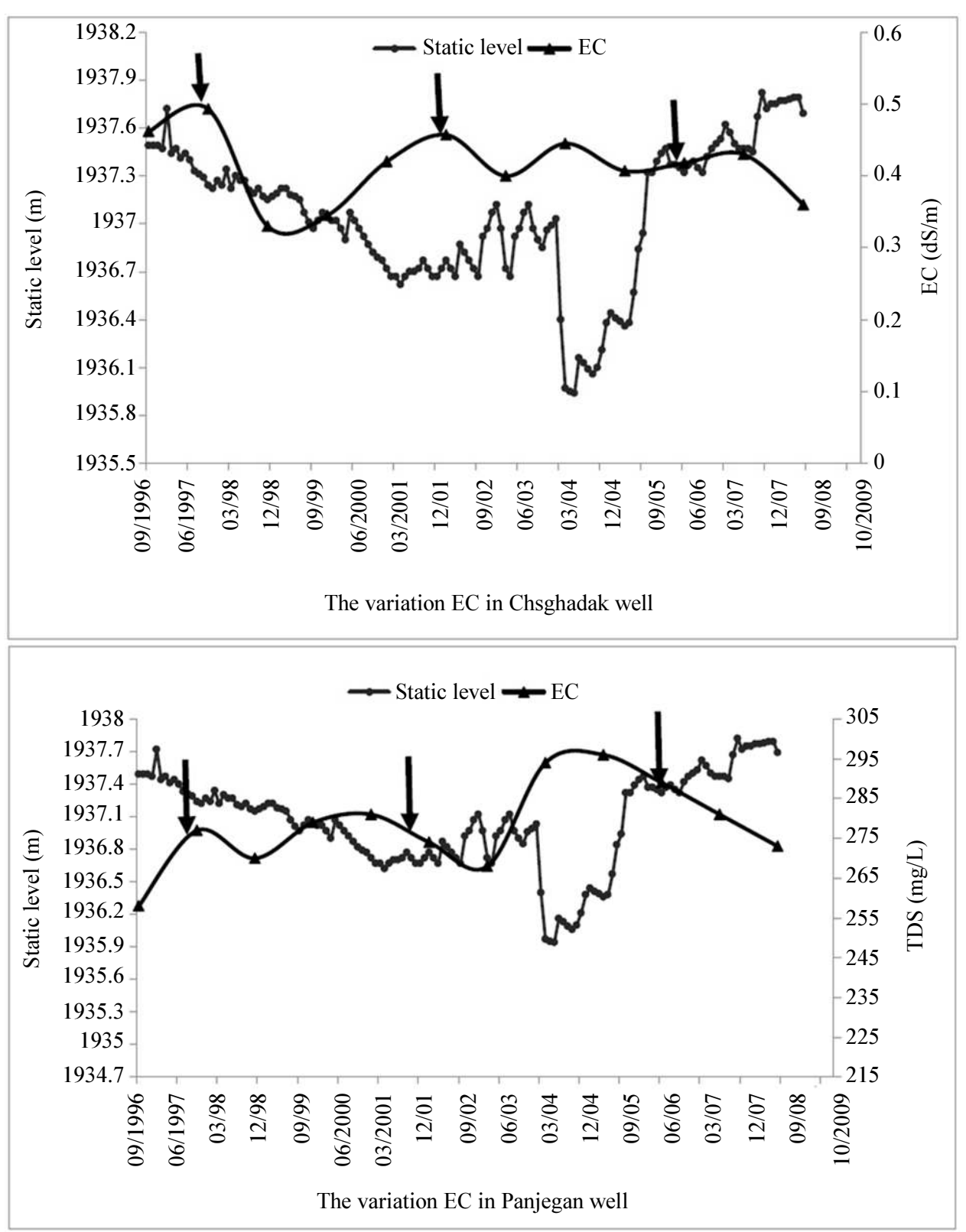

Fig. 11: Effect of artificial recharge facilities on the upstream and downstream boreholes

\section{Conclusion}

According to the results obtained via the CRD model concerning south Shahreza area, the value of recharge in each area related to existing meteorological stations was obtained based on a coefficient of rainfall and considering the total area of region and average annual rainfall in the basin, the total volume of recharged water via rainfall in the south Shahreza area was estimated about 177.2 million cubic meters. The Increased water table in observational boreholes in this area is an evidence of the positive effect of these facilities. The effect of these facilities in different locations varies, such that in some boreholes, up to the 5-meter increase in water table was observed.

In Kohrouyeh facilities, due to high soil permeability, the degree of water table rise is more than other facilities and it reaches to maximum water table rise within less time.

Moreover, the impact range of recharge of Kohrouyeh facilities is more than other facilities.

Given the output of groundwater quality maps of the studied area, it was demonstrated that the concentration of most of the chemical parameters of groundwater gradually increases from the south, 
southwest and west of the plain toward the north and northeast. This phenomenon could be attributed to the direction of groundwater flow and increased water depth in northern areas.

By reviewing the change trend of groundwater quality in upstream and downstream boreholes of artificial recharge facilities and based on impoundment periods it is demonstrated that these facilities are generally effective in improving the quality of groundwater in the direction of groundwater flow, but this improvement is not significant. Hence it is concluded that groundwater quality change is mostly dependent on the groundwater level decline.

\section{Author's Contributions}

All authors contributed to design the study, write and revise the manuscript.

\section{Ethics}

The present Study and ethical aspect were approved by the Isfahan University of the Technology. The present study was approved by the Isfahan University of Technology.

\section{References}

Attarzadeh, A., 1996. On artificial recharge of groundwater in Iran. Water Dev. Magazine Ministry Power, 2: 34-43

Barry, D.A., J.Y. Parlange and M. Crapper, 1999. Approximations for the hantush $\mathrm{M}$ function. J. Hydrol., 221: 91-96.

Behnia, A., 1988. Qanat Development and Maintenance. 1st Edn., Nashre Daneshgahi Center Pub, pp: 236.

Behnke, J.J., 1969. Clogging in surface spreading operations for artificial groundwater recharge. Water Resource Res., 5: 870-896.

Bouwer, H., 2002. Artificial recharge of groundwater. Hydrogeol. Eng. Hydrogeol. J., 10: 121-142.

Cook, P.G., G.R. Walker and I.D. Jolly, 1989. Spatial variability of groundwater recharge in a semiarid region. J. Hydrol., 111: 195-212.
Dettinger, M.D., 1989. Reconnaissance estimates of natural recharge to desert basins in Nevada, U.S.A. by using chloride balance calculations. J. Hydrol., 106: 55-78.

Gerdefaramarzi, S.S. and J.A. Koupaei, 2011. Quantification of groundwater recharge in the karvan aquifer in Isfahan (Iran) using the CRD. Model Water Wastewater, 4: 92- 97

Hantush, M.S., 1967. Growth and decay of groundwater-mounds in response to uniform percolations. Water Resource. Res., 3: 227-234.

Khazaei, E., A.E.F. Spink and J.W. Warner, 2003. A catchment water balance model for estimating groundwater recharge in arid and semiarid regions of south-east Iran. Hydrogeol. J., 11: 333-342.

Minnig, M., C. Moeck, D. Radny and M. Schirmer, 2018. Impact of urbanization on groundwater recharge rates in Dübendorf, Switzerland. J. Hydrol., 563: 1135-1146.

Morel-Seytoux, H.J., C. Miracapillo and M.J. Abdulrazzak, 1990. Areductionist physical approach to unsaturated aquifer recharge from a circular spreading basin. Water Resource. Res., 26: 771-777.

Mousavi, S.F. and D. Kirkham, 1978. Porous media tests of groundwater mounds. Soil Sci., 125: 160-164.

Raeisi, E and F.K. Afzal, 1997. Evalution of Idje artificial groundwater recharge project, Estahban, Iran. Proceedings of the 8th International Conference of Rainwater Catchment Systems, (RCS' 97), Tehran, Iran, pp: 207-219.

Rebhun, M. and J. Schwarz, 1968. Clogging and contamination processes in recharge wells. Water Resource Res., 4: 1207-1217.

WMSD, 2007. Evaluation of flood distribution plans and Bagh Sorkh and Aminabad artificial recharge facility. On Watershed Manag. Studies Design.

$\mathrm{Xu}, \mathrm{Y}$. and G. van Tonder, 2001. Estimation of recharge using a revised CRD method.w 